\title{
Erratum to: Diversification of Caiophora (Loasaceae subfam. Loasoideae) during the uplift of the Central Andes
}

\author{
Marina Micaela Strelin ${ }^{1}$ - José Ignacio Arroyo ${ }^{2,3}$ • Stella Fliesswasser ${ }^{4}$. \\ Markus Ackermann ${ }^{4,5}$
}

Published online: 17 January 2017

(C) Gesellschaft für Biologische Systematik 2017

\section{Erratum to: Org Divers Evol \\ DOI 10.1007/s13127-016-0312-4}

The author Stella Fliesswasser was assigned to a different affiliation in the original publication. The correct affiliation of Dr. Fliesswasser is now correctly reflected in this erratum. Furthermore, the acknowledgements in the published article were not complete. The correct acknowledgements are as follows:

We thank Marcela Moré and Cristina Acosta (IMBIV, CONICET, Universidad Nacional de Córdoba, Argentina); Romina Vidal-Russel (INIBIOMA, CONICET, Universidad Nacional del Comahue); Jorge Strelin, Mateo Martini and Diego Gaiero (CICTERRA, Universidad Nacional de Córdoba, Instituto Antártico Argentino); Matías Ghiglione

The online version of the original article can be found at doi:10.1007/s13127016-0312-4.

Marina Micaela Strelin

marina.strelin85@gmail.com

1 Laboratorio Ecotono, INIBIOMA (Universidad Nacional del Comahue-CONICET), Pasaje Gutierrez 1125, 8400 Bariloche, Rio Negro, Argentina

2 Departamento de Ecología, Facultad de Ciencias Biológicas, Pontificia Universidad Católica de Chile, Santiago, Chile

3 Instituto de Ecología \& Biodiversidad (IEB-Chile), Casilla 653, Santiago, Chile

4 Nees Institut für Biodiversität der Pflanzen, Rheinische Friedrich-Wilhelms-Universität, Meckenheimer Allee 170, 53115 Bonn, Germany

5 Institut für Integrierte Naturwissenschaften - Biologie, Universität Koblenz-Landau, Universitätsstr. 1, 56070 Koblenz, Germany
(Instituto de Estudios Andinos, CONICET, Universidad Nacional de Buenos Aires, Argentina); and the two anonymous reviewers for contributing with their comments and suggestions to the quality of this manuscript. We thank Laura Gatica for editing the English of this manuscript and Maximilian Weigend (Nees Institut für Biodiversität der Pflanzen, Rheinische Friedrich-Wilhelms-Universität, Bonn, Germany) for providing material, funds and data for this study. We also thank John Schenk (College of Science and Mathematics, Georgia Southern University, Statesboro, Georgia, United States) for providing secondary calibration data. M.S has a scholarship from the National Scientific and Technical Research Council, Argentina (CONICET) and J.I. Arroyo holds a scholarship (Beca de Doctorado Nacional) from the National Commission for Scientific and Technological Research, Chile (CONICYT). 